\title{
Promising therapies for treatment of nonalcoholic steatohepatitis
}

\author{
Mazen Noureddin ${ }^{\mathrm{a}, \mathrm{b}}$, Alice Zhang $^{\mathrm{b}}$, and Rohit Loomba ${ }^{\mathrm{c}}$ \\ aFatty Liver Program, Division of Digestive and Liver Diseases, Comprehensive Transplant \\ Center, Cedars-Sinai Medical Center, Los Angeles, CA, USA \\ bDepartment of Medicine, Cedars-Sinai Medical Center, Los Angeles, CA, USA \\ 'Division of Gastroenterology and Division of Epidemiology, University of California, San Diego, \\ La Jolla, CA, USA
}

\section{Abstract}

\begin{abstract}
Introduction-Non-alcoholic fatty liver disease (NAFLD) has become the most common etiology for abnormal aminotransferase levels and chronic liver disease. Its growing prevalence is largely linked to the presence of metabolic syndrome, particularly diabetes and insulin resistance. It is estimated that $60-80 \%$ of the type 2 diabetic population has NAFLD. NAFLD encompasses a range of conditions ranging from simple steatosis to nonalcoholic steatohepatitis (NASH). A subset of patients with hepatic steatosis progress to NASH, while $15-20 \%$ of patients with NASH develop cirrhosis. This progression is thought to be multifactorial, and there are currently no FDAapproved medications for the treatment of NASH.
\end{abstract}

Areas covered-We review drugs currently in Phase II and III clinical trials for treatment of NAFLD and NASH, including their mechanisms of action, relationship to the pathophysiology of $\mathrm{NASH}$, and rationale for their development.

Expert opinion-The treatment of NASH is complex and necessitates targeting a number of different pathways. Combination therapy, preferably tailored toward the disease stage and severity, will be needed to achieve maximum therapeutic effect. With multiple agents currently being developed, there may soon be an ability to effectively slow or even reverse the disease process in many NAFLD/NASH patients.

CONTACT: Mazen Noureddin, mazen.noureddin@cshs.org, Fatty Liver Program, Division of Digestive and Liver Diseases, CedarsSinai Medical Center, 8900 Beverly Blvd, Suite 250, Los Angeles, CA, USA; Rohit Loomba, roloomba@ucsd.edu, NAFLD Research Center, Medicine, Division of Gastroenterology, Division of Epidemiology, University of California at San Diego, 9500 Gilman Drive, La Jolla, CA, USA.

Declaration of interest

R Loomba has served as a consultant to Gilead Sciences, Galmed, Arrowhead, Tobira, Alnylam, Zafgen, Metacrine, Viking, Celgene, Metacrine, Bristol-Myers Squibb, Intercept, Shire, Boehringer Ingelheim, Eli Lily, DeutRx, Genkyotex, Nimbus, RuiYi, Enanta, Isis, Conatus, Scholar Rock, Merck, Profil Institute, Janssen, Corgenix, Roivant, and Adheron. He has received research grant support from Daiichi Sankyo, Gilead Sciences, Merck, Promedior, Galectin, Immuron, Galmed, Tobira, Seimens, Bristol-Myers Sqibb, NGM Biopharmaceuticals, GE Pharmaceuticals and Kinemed. M Noureddin is a consultant for Owlpharma and has served on the advisory board for Abbott. The authors have no other relevant affiliations or financial involvement with any organization or entity with a financial interest in or financial conflict with the subject matter or materials discussed in the manuscript apart from those disclosed. 


\section{Keywords}

Non-alcoholic fatty liver disease; non-alcoholic steatohepatitis; treatment; for non-alcoholic fatty liver disease; treatment for non-alcoholic steatohepatitis

\section{Background}

Nonalcoholic fatty liver disease (NAFLD) is the most common cause of abnormal aminotransferase levels and has overtaken chronic hepatitis $\mathrm{C}$ infection to become the most common etiology of chronic liver disease and cirrhosis especially in certain ethnic groups in the United States [1,2]. Its prevalence has been steadily increasing, particularly in the last quarter century, likely reflecting the rising prevalence of obesity, type II diabetes, and insulin resistance in the general population [3-5]. It is estimated that NAFLD affects 30\% of the general population and $60-80 \%$ of the type 2 diabetic population [6]. NAFLD includes a spectrum of conditions ranging from incidental hepatic steatosis with minimal inflammation also termed as nonalcoholic fatty liver (NAFL), which is the non-progressive subtype to nonalcoholic steatohepatitis (NASH), which is the progressive subtype of NAFLD. NAFL is considered by many experts to be 'the new component' of metabolic syndrome, while NASH is the advanced form that requires an early intervention. It has generally been thought that NAFL will have a benign clinical course [7], while 15-20\% of patients with NASH progress to cirrhosis. However, recent studies have suggested that it is not only NASH that can progress to fibrosis. NAFL may, as well [7,8]. One study showed that there is a 1-stage fibrosis progression over 14.3 years for patients with NAFL compared to 7.1 years for patients with NASH. Presence of hypertension and low aspartate aminotransferase (AST): alanine aminotransferase (ALT) ratio at baseline biopsy were associated with fibrosis progression [8].

While several biomarkers and imaging techniques can help distinguish NAFL from NAFLD with fibrosis, the distinction between NAFL and NASH can only be definitively made through biopsy. Furthermore, NASH is a major risk factor for developing hepatocellular carcinoma (HCC) [9]. The pathophysiology of the development of NASH from NAFL is complex and not completely understood.

\section{Medical need}

There are currently no medications approved by the U.S. Food and Drug Administration for the treatment of NASH. First-line therapy targets lifestyle modification, particularly through diet and exercise. There is currently no universal consensus on the type of diet that NAFLD patients should follow. However, it has been recommended to increase the inclusion of omega-3 fatty acids and healthful foods such as fruit and vegetables. Reduction of intake of saturated fats, carbohydrates, and sweetened drinks (that include fructose) has been also suggested in NAFLD patients [10]. The American Association for the Study of Liver Diseases (AASLD) recommends weight loss of 3-5\% of body weight to improve steatosis and up to $10 \%$ body weight loss to improve necroinflammation [11]. However, these goals might lead to only slight improvement, and it is likely that additional weight loss is required to accomplish significant beneficial effects. This extent of this weight loss is very difficult to 
achieve and maintain for many patients, bringing forth an urgent need for the development of pharmacologic treatment options.

Long-term outcomes in patients with NAFLD have been reported in several studies $[9,12$ 15]. These studies have shown that (1) patients with NAFLD have a higher mortality compared to matched control populations; (2) cardiovascular disease is the most common cause of death; and (3) patients with NASH have higher liver-related mortality. Therefore, the prevention and reversal of NASH have become an area of wide interest, as the prevalence of NAFLD is increasingly rapidly. Current areas of research to discover new treatments include areas that will lead to altering systemic targets related to insulin resistance, lipogenesis, steatosis, steatohepatitis, and fibrosis.

\section{Existing treatment}

The efficacies of vitamin $\mathrm{E}$ and pioglitazone were assessed in the landmark PIVEN trial which randomized 247 subjects with NASH without diabetes to receive (1) daily dose of pioglitazone $30 \mathrm{mg}$, (2) daily dose of vitamin E $800 \mathrm{IU}$, or (3) placebo for a total of 96 weeks [16]. This study's primary end point was improvement in histological features of NASH, specifically the NAFLD activity score (NAS) which includes in the scoring system for steatosis lobular inflammation and hepatocellular ballooning without worsening of fibrosis. The results of the study showed that while vitamin $\mathrm{E}$ yielded a higher rate of patients with improvement in the NAS score compared to placebo (43\% vs. 19\%), there was no difference in improvement with pioglitazone compared to placebo. Secondary outcomes included reductions in serum ALT and AST levels, decreases in hepatic steatosis and lobular inflammation, and resolution of NASH; both vitamin E and pioglitazone achieved significance for these secondary outcomes. Despite this trial showing improvement in histological features of NASH, the clinical use of vitamin E is limited by lack of knowledge about its long-term effects, as well as the need for studies in other patient populations such as patients with diabetes and known cirrhosis [17]. The use of pioglitazone is used sparingly, as its adverse effects include weight gain even after discontinuation of the drug, counteracting patients' attempts for weight loss.

The bile derivative obeticholic acid (OCA, Intercept Pharmaceuticals, Inc., New York, New York), an activator of the farnesoid X nuclear receptor, underwent testing in the Farnesoid X Receptor Ligand Obeticholic Acid in NASH Treatment (FLINT) trial [18]. In this 72-week multicenter trial, 283 noncirrhotic NASH patients were randomized to receive either OCA $25 \mathrm{mg}$ daily or placebo for a total of 72 weeks. The primary end point was improvement in centrally scored liver histology defined as a decrease in the NAS by at least 2 points without worsening of fibrosis from baseline to the end of treatment. Due to a planned interim analysis at 24 weeks, which showed a relative $-24 \%$ change $(p=0.0024)$ in ALT, treatment was discontinued in 64 patients. Fifty ( $45 \%$ ) of the 110 OCA patients who were intended to have baseline and posttreatment biopsies showed improvement in NAS score; this is in comparison to $23(21 \%)$ of the 109 in the placebo group $(p=0.0002)$. However, the resolution of definitive NASH did not differ between the two groups. The OCA treatment group showed increases in triglycerides and LDL cholesterol as well as a modest decrease in HDL, raising the necessity for long-term monitoring. Furthermore, 23\% of the OCA group 
reported pruritus. Although improvement in the liver histology provides encouraging results, long-term effects are unknown, as the improvement of liver enzymes regressed upon discontinuation of OCA. This suggests that to obtain the therapeutic benefit of OCA, longterm administration is necessary. Further evaluation is imperative to determine long-term efficacy, safety, and tolerability.

Several small studies have evaluated the use of pentoxifylline on liver histology [19,20]. In one study, patients with NASH were given pentoxifylline $1200 \mathrm{mg}$ daily for 1 year and found to have statistically significant reduction in steatosis and lobular inflammation compared to placebo using NAS [21]. Another trial also demonstrated improvement of steatosis and cellular ballooning $(p<0.05)$. Despite this histological improvement, metabolic parameters along with serum transaminases were not improved. Adverse effects reported included nausea and vomiting. Further studies are needed to explore its efficacy.

The AASLD guidelines recommend weight loss as first-line therapy. Vitamin $\mathrm{E}$ at a daily dose of $800 \mathrm{IU} /$ day is first-line therapy for nondiabetic patients with NASH but is not recommended for patients with diabetes, NAFLD without liver biopsy, cirrhosis, or cryptogenic cirrhosis. Pioglitazone can be used for treatment with biopsy-proven NASH with careful consideration that the study population did not include diabetics and that longterm safety is not established.

\section{Current research goals}

The currently available agents that were previously described have been shown to have unfavorable side effects and unknown long-term outcomes. As attempts for weight loss are often insufficient, new pharmacologic treatments are urgently needed. Existing research goals include discovering medications that lead to (1) NASH resolution with fewer side effects and favorable cardiovascular and metabolic effects; (2) reversal of fibrosis measured by reduction of portal pressure measurements, improving histological fibrosis, and/or preventing progression and decompensation.

\section{Scientific rationale}

In this review, we cover therapeutic agents that have shown some benefit in NASH and introduce new interventions currently in the clinical trial pipeline. The emphasis of the review is to highlight agents currently in the Phase $2 / 3$ stage of clinical development and assess the basis of their mechanisms of action and the rationale for their development.

\subsection{Pathophysiology of NASH}

The pathophysiology that underlies the mechanisms for development of steatosis and progression to NASH is not fully defined although a number of theories have been proposed [22-24]. This paper is not intended to be an all-encompassing review discussing all the pathways involved, but rather to highlight several known pathways that upcoming therapeutic agents are targeting. 
It is generally accepted that the development of NAFLD requires a 'first-hit' which takes the form of hepatic fat accumulation. Hyperinsulinemia and insulin resistance, commonly associated with obesity and metabolic syndrome, lead to triglyceride accumulation in the liver. This overall process involves an imbalance of (1) lipolysis (hydrolysis of triglycerides into free fatty acids and glycerol) within adipose tissue; (2) dietary intake; and (3) de novo lipogenesis in the liver, coupled with dysregulation of handling of excess fat from the liver $[22,23]$. Free fatty acids can be used in various ways, including beta-oxidation, packing, and exportation from the liver as very-low-density lipoprotein (VLDL), or re-esterification to triglycerides and storage as fat droplets. Therefore, overall fat accumulation can arise from increased synthesis and import, decreased fat exportation, or a combination of both processes [25].

Beyond lipid accumulation, multiple 'second hits' are needed to trigger inflammation, cellular injury, and eventual fibrosis. Examples of 'second hits' include proinflammatory cytokines, oxidative stress, iron accumulation, mitochondrial dysfunction, alterations in the gut-liver axis, and endotoxins [22,23]. It is thought that an increase in reactive oxygen species (ROS) is one of the main culprits in NASH development. Metabolism of fatty acids primarily occurs in the liver through mitochondrial beta-oxidation; however, this enzymatic process can become overwhelmed with excessive levels of fatty acids. Once the mitochondria capacity is exhausted, beta-oxidation is shunted toward smooth endoplasmic reticulum and peroxisomes [26,27], which inadvertently creates by-products including ROS that cause oxidative stress and activation of proinflammatory pathways $[28,29]$.

The presence of chronic inflammation is closely associated with progression of NAFL to NASH. This transition is heavily mediated through the transforming growth factor beta (TGF- $\beta$ ) signaling pathway which activates Kupffer cells and influences expression of proinflammatory cytokines including tumor necrosis factor-alpha (TNF- $\alpha$ ), interleukin-6 (IL-6), and IL-1 $\beta$ [30]. Serum levels of TNF- $a$ have been found to be elevated in NASH patients [31,32] and correlate with histological severity [33]. TNF-a promotes insulin resistance [34] creating a vicious cycle of increasing hepatic steatosis. Of note, other signaling pathways including those regulated by farnesoid-X receptor (FXR), peroxisome proliferator-activated receptors (PPAR), vitamin D receptor (VDR), liver-X-receptor (LXR), and retinoid receptors are also being recognized as therapeutic targets for preventing and reversing NASH [35].

Activation of immune cells and alterations in the bacterial microbiome have also been implicated in the pathogenesis of NASH. Toll-like receptors (TLRs) play a critical role in the innate immune system by sensing bacterial and viral components, enabling the host to recognize invading pathogens and mount a host response. Stimulation of the TLRs triggers a proinflammatory cascade by the immune cell. Activation is appropriate in response to exposure to exogenous pathogens; however, in NASH, there is associated bacterial overgrowth and increased membrane permeability [36]. This results in exaggerated levels of TLR activation in the liver, leading to a continuous state of inflammation causing tissue injury [37]. Moreover, bacterial overgrowth results in production of alcohol [38] and lipopolysaccharides - both of which upregulate TNF-a production in hepatic Kupffer cells, furthering inflammation [39]. 
The common final pathway for almost all chronic liver diseases including NASH leads to fibrosis, which is characterized by excessive extracellular deposition of collagen [40]. The end state of fibrosis known as cirrhosis has known complications related to portal hypertension and is a risk factor for HCC. Therefore, both the prevention and reversal of fibrosis present themselves as enticing therapeutic interventions. Potential targets include (1) reducing activation of hepatic stellate cells through PPAR regulation [41]; (2) inhibition of angiotensin which promotes myofibroblast survival [42]; (3) inhibition of interstitial crosslinking of collagen; and (4) inhibition of other growth factors such as fibroblast growth factor (FGF), platelet-derived growth factor (PDGF), connective tissue growth factor (CTGF), and TGF $\beta-1[43,44]$.

\section{Competitive environment}

A large number of therapeutic agents are being tested in phase 2/3 clinical trials (see Table 1). A search for medications under evaluation was performed using the clinicaltrials.gov clinical trial registry. In this review, treatments are divided into sections based on their targets within the pathophysiology of NASH. These include (1) systemic targets related to steatosis, glucose metabolism, and lipogenesis; (2) targets related to immune modulators; (3) targets related to oxidative stress; (4) targets related to fibrosis; and (5) targets related to apoptosis (Figure 1).

\subsection{Targets related to steatosis, glucose metabolism, and lipogenesis}

Aramchol (Galmed Pharmaceuticals, Tel Aviv, Israel) works as a fatty acid-bile acid conjugate and inhibitor of the stearoyl-coenzyme A desaturase 1 enzyme (SCD1) that is involved with modulation of hepatic fatty acid metabolism. By inhibiting SCD1, synthesis of fatty acids is reduced while beta-oxidation is increased, resulting in an overall decrease in hepatic stores of triglycerides and fatty acid esters $[45,46]$. In murine models, aramchol treatment reduced the amount of liver fat in NAFLD and decreased total liver lipids by about $30 \%$ in 4 weeks $(p<0.03)$ [47]. A phase 2 , randomized, double-blind, placebo-controlled trial enrolled 60 patients with biopsy-confirmed NAFLD (six with NASH) who were given aramchol 100 or $300 \mathrm{mg}$ daily for 3 months [48]. While the decrease in liver fat was significant in the 300-mg/day group compared to placebo (12.57\% decrease vs. $6.39 \%$ increase, $p 0.02$ ), the decrease seen in the aramchol 100-mg/day group did not reach statistical significance suggesting a dose-response relationship. Due to the short duration of the study, repeat biopsy was not warranted which prevented the study from being able to assess for change in fibrosis. A phase $2 \mathrm{~b}$ trial is currently using higher doses of aramchol (400 and $600 \mathrm{mg}$ ) in patients with biopsy-confirmed NASH to assess changes in liver triglyceride concentration as measured by magnetic resonance spectroscopy (MRS) and safety and efficacy of the medication. ClinicalTrials.gov identifier: NCT02279524.

BMS-986036 (Bristol-Myers Squibb, New York, New York) acts as an agonist for FGFs, a group of proteins produced by the liver that have multiple metabolic functions including energy homeostasis, glucose-lipid metabolism, and insulin sensitivity [49]. FGF21 directly regulates lipid metabolism by reducing lipid accumulation in the liver and inhibiting the lipolysis of white adipose tissue, lessening the levels of circulating free fatty acids [50-52].

Expert Opin Emerg Drugs. Author manuscript; available in PMC 2018 April 18. 
FGFs further mitigate 'multihits' of the pathogenesis of NASH through reduction of oxidative stress, endoplasmic reticulum stress, chronic inflammation, and mitochondrial dysfunction [53]. Multiple murine model experiments have shown that administration of FGF21 significantly reverses hepatic steatosis while improving hepatic and peripheral insulin sensitivity, reducing body weight, and increasing overall energy expenditure [54-56].

A phase 2, double-blind, placebo-controlled trial is recruiting patients with biopsyconfirmed NASH with elevated BMI > 30 to test for changes in hepatic fat fraction as measured by MRI and to assess the safety of BMS-986036. ClinicalTrials.gov identifier: NCT02413372.

Elafibranor (GFT505, Genfit, Lille, France) is a peroxisome proliferator-activated $a / \delta$ receptor agonist. PPARa/ $\delta$ are nuclear receptors that have the potential to improve NASH through a multitude of mechanisms including increase of fatty acid oxidation, improvement of lipid profiles, and increase in insulin sensitivity, as well as through anti-inflammatory and antifibrogenic effects. In a mouse model of NASH, GFT505 significantly reduced serum ALT levels, decreased hepatic lipid accumulation, and inhibited proinflammatory (IL-1 $\beta$, TNF- $\alpha$, and F4/80) and profibrotic (TGF- $\beta$, tissue inhibitor of metalloproteinase 2, collagen type I, a 1, and collagen type I, a 2) gene expression [57]. In a phase 2 trial for GFT505, due to the unexpected rate of resolution of NASH in patients randomized to placebo who had early NASH (NAS score $=3$ ), the study as initially designed did not enable the trial to meet the primary end point, reversal of steatohepatitis without worsening of fibrosis [58].

However, after correcting for baseline severity of fibrosis, GFT505 $120 \mathrm{mg}$ daily met the end point. These findings suggest a clinical benefit in patients with more advanced disease.

GFT505 also showed beneficial effects on metabolic parameters including decreased plasma triglycerides, increased HDL, and improved insulin sensitivity. It was found to have a favorable safety profile, demonstrating no PPAR $\gamma$ activity to cause water retention or cardiac insufficiency. A phase 3 trial to evaluate the effect of elafibranor treatment compared to placebo on (1) histological improvement and (2) all-cause mortality and liver-related outcomes in patients with NASH and fibrosis has started. ClinicalTrials.gov identifier: NCT02704403.

Liraglutide (Novo Nordisk, Bagsværd, Denmark) is a glucagon-like peptide-1 (GLP-1) agonist that is widely used in the treatment of type 2 diabetes mellitus to improve glycemic control. GLP-1 improves glycemic control through various pathways including increasing insulin release and diminishing glucagon secretion [59,60]. In several studies, GLP-1 also directly improved hepatic steatosis [61-64]. In murine models, administration of a GLP-1R agonist to Lep(ob)/Lep(ob) mice significantly reduced body weight $(8.3 \%)$, liver mass (14.2\%), plasma ALT, and triglycerides [65]. The LEAN trial was a phase 2, multicenter, double-blind, placebo-controlled, randomized trial investigating the effects of 48-week treatment with liraglutide $1.8 \mathrm{mg}$ on liver histology [66]. Posttreatment, follow-up liver biopsies showed that nine of 23 liraglutide patients (39\%) had resolution of their NASH without worsening fibrosis using NAS, while this was seen in only two of $22(9 \%)$ placebo patients. Treatment also showed an average $5 \mathrm{~kg}$ greater weight loss compared to placebo and $0.45 \%$ decrease in hemoglobin A1c, although these measures fell slightly short of statistical significance. 
Oltipraz is a synthetic dithiolethione that has an antisteatotic effect through inhibition of liver X receptor alpha (LXR-a) and disruption of LXR-a-dependent lipogenesis from hepatocytes. In a murine model, rats treated with oltipraz were found to have significant improvement in histology, as measured by decrease in liver fibrosis area and immunohistochemistry expression for alpha smooth muscle actin (a-SMA), an indicator for hepatic stellate cell activity [67]. In a phase 2 , multi-center, randomized controlled trial, oltipraz in doses of $30 \mathrm{mg}(\mathrm{n}=22)$ or $60 \mathrm{mg}(\mathrm{n}=24)$ was given twice daily for a total of 24 weeks [68]. There were dose-dependent absolute changes in liver fat content as measured by MRS: $-3.21 \pm 11.09 \%$ in the placebo group, $-7.65 \pm 6.98 \%$ in the low-dose group, and $-13.91 \pm 10.65 \%$ in the high-dose group. BMI and NAS were significantly decreased in the oltipraz 60-mg group compared to placebo. However, changes in insulin resistance, liver enzymes, and inflammatory cytokines were comparable among the groups.

Sitagliptin (Merck \& Co., Inc., Kenilworth, New Jersey) functions as an inhibitor of dipeptidyl peptidase (DDP4), the enzyme that breaks down incretins GLP-1 and GIP. Like GLP-1 agonists, DDP4 inhibitors have been commonly used for treatment of patients with type 2 diabetes; however, its therapeutic value in NASH has been recently studied. In an open-label, single-arm, observational pilot study, 15 diabetics with NASH were administered 1 year of treatment with sitagliptin $100 \mathrm{mg}$ once daily and monitored for changes in liver histology, BMI, and laboratory measurements associated with NASH. This study found a significant decrease in hepatocyte ballooning $(p=0.014)$ and NASH scores $(p=0.04)$, while reduction in the steatosis score reached borderline significance $(p=0.054)$ [69].

Furthermore, significant reductions in serum AST and ALT levels and BMI were observed. However, a recent randomized, double-blind, placebo-controlled study showed that sitagliptin was not more effective than placebo for improving liver fat and liver fibrosis measured in patients with NAFLD [70].

\subsection{Targets related to the immune modulators}

JKB-121 (Jenken Biosciences, Research Triangle Park, North Carolina) is a TLR4 antagonist currently under investigation as treatment for NASH. TLRs are a group of receptors that have a vital role in the activation of the innate immune system through recognition of pathogen-associated molecular patterns (PAMPs) [71,72]. Endogenous components released from dying cells can activate TLRs initiating a proinflammatory NF$\kappa \beta$ cascade and production of TNF- $\alpha$ and IL-6 [71-74]. TLRs appear to play a crucial role in the pathophysiology of a multitude of liver diseases [37], which potentially explains its wide expression on many types of liver cells including hepatocytes [37,75], Kupffer cells [37,76], sinusoidal endothelial cells [77], and hepatic stellate cells [78-80]. Serum TLR4 levels have been shown to be elevated in NASH patients compared to healthy controls and to increase with worsening stages of fibrosis [81]. Preliminary data show that in mouse models, features of NASH are attenuated in TLR4 and TLR4 coreceptor myeloid differentiation factor (MD-2) knockout mice. While methionine choline-deficient diet was associated with increased serum ALT levels in genotype controls, this effect was attenuated in TLR4 KO mice. Furthermore, markers of inflammation including serum TNF- $a$ and the nicotinamide adenine dinucleotide phosphate-oxidase (NADPH oxidase) complex mRNA expression were significantly lower in TLR4 KO mice [82]. A phase 2, double-blind, randomized controlled 
trial is testing the use of JKB-121 in patients with biopsy-proven NASH to assess for safety and changes in baseline ALT and percentage fat content of the liver as measured by MRI and MRS. ClinicalTrials.gov identifier: NCT02442687.

Lactobacillus and other probiotics are under investigation because the role of altered gut microbiota has been linked to development of obesity $[83,84]$ and susceptibility to liver injury [85]. The intestinal flora consists of $10^{4}$ microorganisms that maintain a symbiotic relationship with the host. Gut microbiota produce endotoxins, including lipopolysaccharides (LPS), lipopetides, unmethylated DNA, and double-stranded RNA, which reach the liver and undergo phagocytosis by Kupffer cells [86]. The exposure to these endotoxins can incite an inflammatory response, contributing to the progression from simple steatosis to NASH. Several studies have shown that treatment with probiotics has the potential to improve parameters of liver damage, including a double-blinded trial in 2011 showing that treatment with a mixture of probiotics (Lactobacillus bulgaricus and Streptococcus thermophilus) in 28 patients with biopsy-proven NASH improved serum levels of ALT, AST, and GGT compared to placebo [87]. Another study in 2012 investigated the effect of probiotics in NASH subjects on improvement in liver histology. Posttreatment liver biopsy compared to baseline biopsy exhibited improvement in steatosis and NASH activity index along with decreased levels of TNF-a, CRP, AST, and HOMA-IR compared to subjects randomized to lifestyle modification only [88]. A recent phase 3 trial enrolled 52 patients with NASH and randomized them to either 28-week treatment with synbiotics (a combination of probiotics and prebiotics) or placebo. Both groups were also advised to engage in lifestyle modification with diet and exercise. The study showed significant reductions in serum ALT, AST, GGT, C-reactive protein, total NF- $\kappa \beta$, and fibrosis score as measured by transient elastography [89] The use of lactobacillus casei shirota is being tested in a phase 2 trial assessing for reduction in serum M30 antigen levels and other indicators of hepatocellular injury and fibrosis in patients with elevated M30 antigen levels (cutoff: >200$800 \mathrm{U} / \mathrm{L}$ ) at screening and hepatic steatosis on ultrasound or histologically confirmed NASH.

Solithromycin (Cempra Pharmaceuticals, Chapel Hill, North Carolina) is a ketolide antibiotic that has been shown to not only have antibacterial effects, but also antiinflammatory and immunoregulatory effects [90]. In one study, use of solithromycin exerted inhibitory effects on TNF-a/CXCL8 production and MMP9 activity in monocytic cells in mice with cigarette smoke-induced airway inflammation. These findings of reduced TNF- $a$ and MMP9 activity in monocytic cells were corroborated in patients with chronic obstructive pulmonary disease treated with solithromycin [91]. In a NASH mouse model, administration of solithromycin once daily for 4 weeks significantly reduced hepatocyte ballooning and NASH score [92]. The mean NASH activity score (NAS) for solithromycintreated mice was $3.0+0.9(\mathrm{n}=8)$ compared to $5.4+0.5(\mathrm{n}=8, p<0.0001)$. The use of solithromycin is being tested in a phase 2 trial in NASH patients that is evaluating effects on hepatic histology using NAS and measuring changes in steatosis, hepatocellular ballooning score, and grades of inflammation on liver biopsy. ClinicalTrials.gov identifier: NCT02510599. 
Vitamin D has a broad spectrum of actions including immune modulation, cell differentiation and proliferation [93], regulation of inflammation [94], and regulation of glucose and lipid metabolism [95,96], making it an appealing therapeutic target for NASH. Dietary vitamin D2 or sunlight-derived D3 is metabolized to 25-hydroxyvitamin D in the liver before it is transported to the kidney where it is hydroxylated to become the biologically active form 1a,25-dihydroxyvitamin $\mathrm{D}$. To exert its biological effect, $1,25(\mathrm{OH}) 2 \mathrm{D}$ binds to vitamin $\mathrm{D}$ receptors which are not only found on bone and skeletal muscle, but also expressed in the immune system, liver, and endocrine system [97,98]. Animal studies reveal that VDR knockout mice spontaneously develop liver fibrosis [99]. A murine model showed that with phototherapy, increased $25(\mathrm{OH}) \mathrm{D}$ and 1,25(OH)2D levels were able to reduce hepatocyte inflammation, fibrosis, and apoptosis compared to control. Insulin resistance improved, serum adiponectin increased, and inflammatory gene expression TNF- $\alpha$ and TFG- $\beta$ were reduced [100]. Epidemiologic evidence suggests that patients with low vitamin D levels are most susceptible to development of NASH; one meta-analysis found that patients with NASH were $26 \%$ more likely to have low levels of vitamin D compared to the control subjects [101]. A small, double-blinded, placebo-controlled study assigned NASH patients to either 50,000 IU vitamin D or placebo every 2 weeks for 4 months [102]. There were no significant differences between groups in liver enzymes, insulin sensitivity, or grades in hepatic steatosis. However, levels of hsCRP and malondialdehyde (MDA), both markers of lipid peroxidation, were decreased in patients given vitamin $\mathrm{D}$, suggesting that it may be useful to mitigate inflammation. There is one phase 2 trial and one phase 3 trial in the pipeline looking to evaluate whether vitamin D supplementation can reduce serum ALT levels or improve NAS scores, respectively. ClinicalTrials.gov identifiers: NCT01571063, NCT01623024.

\subsection{Targets related to oxidative stress}

GS-4997 (Gilead Sciences, Inc., Foster City, California) is a selective small-molecule apoptosis signal-regulating kinase (ASK1) inhibitor which works to mitigate the profibrotic response to ROS. In response to ROS, ASK1 is upregulated activating the p38 and JNK pathways, which induce hepatic stellate cells to increase collagen production. In murine models, GS-4997 showed a reduction in hepatic steatosis and fibrosis along with an improvement in metabolic measurements associated with development of NASH [103]. After C57BL/6 mice were fed a western-style diet to induce NASH, the mice were randomized to treatment with control or an ASK1 selective inhibitor. The ASK1 inhibitor treatment group showed a significant reduction in body weight and fasting blood glucose levels (17\% and 13\%, respectively). Moreover, reductions were seen in plasma levels of AST, ALT, and cholesterol. On histology, there was a $68 \%$ reduction in steatosis and $84 \%$ reduction in fibrillar collagen area, corresponding to reductions in a-SMA and p-P38 expression. GS-4997 is currently being evaluated in a phase 2 clinical trial recruiting patients with biopsy-proven NASH with fibrosis stages F2/F3 to assess the safety, tolerability, and efficacy of GS-4997 alone or in combination with simtuzumab, a LOXL2 antibody targeting collagen cross-linking. ClinicalTrials.gov identifiers: NCT02466516.

Omega-3 is classified as a polyunsaturated fatty acid (PUFA) derived from a-linolenic acid [104]. It is an essential fatty acid obtained through diet [105] that is a key component of the 
cellular membrane and helps determine membrane fluidity. In addition, omega-3 modulates the behavior of membrane-bound receptors and enzymes [106]. Omega-3 PUFAs influence liver lipid homeostasis through regulation of fat accumulation and elimination via downregulation of sterol regulatory element binding protein-1 (SREBP-1) [107,108] and nuclear factor-Y (NF-Y) transcription factors [109]. This results in a decrease in expression of lipogenic genes, reducing triglyceride storage in the liver. Conversely, it upregulates peroxisomal proliferator activated receptor-alpha (PPAR-a), promoting hepatic free fatty acid oxidation and degradation $[107,110]$. The overall effect is a reduction in intrahepatic lipids. Furthermore, omega-3 appears to have a protective effect through inhibition of proinflammatory cytokines such as TNF-a, IL-1, and IL-6 [111]. In rodents, omega-3 PUFA depletion has been shown to contribute to steatosis and insulin resistance, with eventual development of NASH [112,113]. Further, murine experimental models have supported the hepatoprotective effect of omega-3s, demonstrating reversal of hepatic steatosis in leptindeficient obese mice [114]. Omega-3s as a potential treatment for NASH are being explored in one phase 2 trial and two phase 3 trials evaluating for changes in histology and intrahepatic fat content. To date, there is no human data available on efficacy.

S-adenosylmethionine (SAMe) is the principal biological methyl donor made in all mammalian cells. SAMe metabolism predominantly occurs in the liver and is the principal methyl donor in a variety of biochemical reactions including transmethylation, transsulfuration, and polyamine synthesis $[115,116]$. The enzyme methionine adenosyltransferase (MAT) combines methionine and adenosine triphosphate to produce SAMe which donates its methyl group to various hormones, neurotransmitters, nucleic acids, proteins, phospholipids, and drugs [116,117]. SAMe plays a role in establishing membrane fluidity as measured by the proper ratio of phosphatidyletanolamine (PE) to phosphatidylcholine (PC) through the methylation of phospholipids. It is this PE/PC ratio that may play a role maintaining cellular membrane integrity [118] and has been implicated in the progression from steatosis to NASH [119]. Preclinical data reveal that mice deficient in MAT1A or glycine-N-methyltransferase (GNMT), key enzymes in SAMe biosynthesis and degradation, respectively, develop NASH and HCC [115]. In addition, reduced SAMe levels have been shown to increase proinflammatory responses. In a multicenter trial, 62 patients with cirrhosis due to alcoholic liver disease were randomized to either SAMe or placebo for treatment for up to 2 years [120]. All-cause mortality was not statistically reduced; however, when excluding subjects with advanced cirrhosis (Child-Pugh score C), the results showed a significant reduction in mortality ( $29 \%$ vs. $12 \%, p=0.025)$. The therapeutic benefit of SAMe at three dosage levels $(1000,1500$, and $2000 \mathrm{mg})$ is now being tested in patients with NASH in a phase 3 trial to assess for methionine elimination half-life and changes in liver enzymes and metabolic parameters. ClinicalTrials.gov identifier: NCT01754714.

\subsection{Targets for fibrosis}

Cenicriviroc (CVC, Tobira Therapeutics, Inc., South San Francisco, California) acts as a dual inhibitor of C-C chemokine receptor type 2 (CCR2) and C-C chemokine receptor type 5 (CCR5) pathways which have key roles in the development of inflammation and fibrosis. CCR2 and CCR5 receptors are expressed on Kupffer cells, hepatic stellate cells, monocytes, 
and macrophages and, when activated, promote recruitment of these cells to the liver, inducing inflammation and fibrogenesis. In thioglycollate-induced mouse models, CVC reduced macrophage and monocyte migration by $62.1 \%$ compared to positive control dexamethasone $(p<0.001)$ [121]. CVC also significantly decreased NAS scores and mean Sirius red-positive areas in a mouse NASH model [122]. As CVC has been tested more extensively in the treatment of HIV patients, its safety profile has largely been established. It is generally well tolerated, with the most common adverse effects reported to be nausea, diarrhea, headache, rash, and fatigue. The ongoing Efficacy and Safety Study of Cenicriviroc for the Treatment of Nonalcoholic Steatohepatitis (NASH) in Adult Subjects With Liver Fibrosis (CENTAUR) trial by Tobira has been granted FDA fast track approval for testing in NASH patients with fibrosis (CRN stage 1-3) to evaluate for resolution of NASH with no worsening of fibrosis stage.

GR-MD-02 (Galectin Therapeutics, Norcross, Georgia) functions as a galectin-3 antagonist, and preclinical results to date are promising. Galectins are a group of proteins with a carbohydrate-binding domain capable of binding to terminal galactose residues on glycoproteins; they have been implicated in the pathophysiology of NASH and liver fibrosis $[123,124]$. Under normal physiologic conditions, galectin-3 expression is ubiquitous, particularly in immune cells, albeit at low levels. However, in states of acute or chronic inflammation, it is overexpressed and likely induces the deposition of fibrous tissue $[124,125]$. The critical role of galectins is evidenced by experimentation with Gal-3 null mice that are found to be resistant to development of liver fibrosis despite toxin exposure [126] and to lung fibrosis even after treatment with bleomycin [127]. In a phase 1, randomized, placebo-controlled trial, patients with NASH and advanced (Brunt stage 3) fibrosis were randomized to treatment with water or escalated doses of GR-MD-02 $(2,4$, and $8 \mathrm{mg} / \mathrm{kg}$ ) for a total of four doses [128]. GR-MD-02 was found to be safe and well tolerated with no reported serious adverse events. The GR-MD-02 8-mg/kg treatment group had a significant reduction in FibroTest Scores, a composite of five individual blood tests that collectively correlate with the extent of liver fibrosis. The reduction was most attributed to the lowering of a-2 macroglobulin, a major non-immunoglobulin protein in plasma that is known to have a role in inhibiting proteases including collagenase [129] FibroScan evaluations were performed at baseline, day 38 , and day 65 in a subset of patients (five from GR-MD-02 group and three from placebo group). No observed change in liver stiffness was seen in the three placebo patients; however, three of the five patients treated with GR-MD-02 showed a $20 \%$ reduction in liver stiffness from baseline. The other two GR-MD-02 patients had a 50\% decrease from baseline. Despite these initial encouraging results, given the small sample size, further evaluation is warranted. Galectin Therapeutics is investigating the use of GR-MD-02 in patients with NASH and advanced fibrosis in a phase 2 trial that is assessing changes in liver fibrosis and liver stiffness. Another phase 2 trial is evaluating the efficacy of GR-MD-02 for reducing the hepatic venous pressure gradient (HVPG) as a measure of portal pressure in NASH patients with portal hypertension and cirrhosis. ClinicalTrials.gov identifier: NCT02421094.

Losartan is an angiotensin receptor blocker (ARB) which disrupts the renin-angiotensin system that is thought to be upregulated in the development of chronic liver disease. Angiotensin-II (AT-II) induces proliferation of hepatic stellate cells and upregulates the 
expression of TGF- $\beta$, inducing liver fibrogenesis [130]. AT-II receptor activation induces TFG- $\beta 1$ which upregulates the production of matrix proteins. It also prevents matrix degradation and stimulates expression of integrins which collectively facilitate matrix production [131]. Using a methioninecholine-deficient rat model for NASH, treatment with ARB diminished increases in AST and activation of hepatic stellate cells and reduced the extent of liver fibrosis by $70 \%$ compared to placebo. Expression of type 1 collagen a 1 mRNA was significantly reduced, corresponding to a $51 \%$ reduction in TGF- $\beta 1 \mathrm{~m}$ RNA expression 132]. In an observational study, eight patients with NASH and hypertension were treated with losartan $50 \mathrm{mg}$ daily for 48 weeks. As expected, systemic blood pressure was significantly decreased in all patients. Serum levels of AST, ALT, GGT, TGF- $\beta 1$, and serum ferritin concentration were all significantly reduced. Histological improvement of necroinflammation occurred in five patients, reduction in hepatic fibrosis in four, and disappearance of iron deposition in two. No adverse effects were observed in the study [133]. The phase 3 Anti-Fibrotic Effects of Losartan In Nash Evaluation (FELINE) trial that assessed changes in fibrosis score in patients with NASH and fibrosis (Kleiner F1-F3) after treatment with losartan compared to placebo has been completed, but results have not yet been published.

Simtuzumab (Gilead Sciences, Inc., Foster City, California) is a humanized monoclonal antibody directed against LOXL2. LOXL2 is an enzyme that promotes cross-linking of collagen fibers and is thought to play a vital role in tumor progression and cancer metastasis. Increased cross-linking of interstitial collagen strengthens the tissue, making it more resistant to degradation [134]. Preclinical data in experimental animal models have shown that LOXL2 inhibition resulted in a marked reduction in activated fibroblasts and prevented cross-linking of collagen [61]. Inhibition of fibroblasts will lead to decreased production of growth factors and cytokines and decreased TGF- $\beta$ pathway signaling. In a study of 20 patients with liver fibrosis from diverse etiologies, either of two doses of simtuzumab (10 or $30 \mathrm{mg} / \mathrm{kg}$ ) were infused over $1 \mathrm{~h}$ every 2 weeks for a total of three infusions [135]. Of the seven patients with aminotransferase elevations prior to treatment, six experienced a reduction in aminotransferases after the second infusion. Simtuzumab appeared to be well tolerated with the most frequent reported adverse effects being abdominal pain, musculoskeletal pain, and headache. A phase 2 trial is comparing event-free survival, safety, and the mean change from baseline in hepatic venous pressure gradient in patients with compensated cirrhosis secondary to NASH treated with simtuzumab (700 or $400 \mathrm{mg}$ administered by intravenous infusion over 30 min every 2 weeks) or placebo. Another phase 2 trial is evaluating whether simtuzumab ( 75 or $125 \mathrm{mg}$, administered by subcutaneous injection once weekly) is effective for preventing the histological progression of liver fibrosis and the clinical progression to cirrhosis in NASH patients with advanced liver fibrosis but not cirrhosis. A third phase 2 trial is assessing the safety and tolerability of simtuzumab combined with GS-4997 compared to GS-4997 alone in NASH patients with fibrosis stages F2-F3. ClinicalTrials.gov identifier: NCT01672879, NCT01672866, NCT02466516. 


\subsection{Targets of apoptosis}

GS-9450 (Gilead Sciences, Inc., Foster City, California) behaves as a potent caspase inhibitor involved in cell apoptosis. Caspase activity triggers the process of apoptosis in which a functioning cell transforms to an apoptotic body characterized by cell shrinkage and nuclear condensation. Apoptosis is a normal mechanism to maintain cellular homeostasis but can become upregulated in disease states, particularly those involving the liver [136]. A multitude of liver diseases have been associated with increased caspase activity including nonalcoholic and alcoholic steatohepatitis, chronic hepatitis B and C virus infection, and cholestatic injury. Preclinical data in mouse models showed that treatment with caspase inhibition reduced apoptosis associated with both methioninecholine-deficient and high-fat diets. Although treatment did not reduce steatosis, there were reductions in histological inflammation, plasma ALT levels, and measurements of oxidative stress [137]. A follow-up, phase 2, randomized, double-blinded, placebo-controlled trial sponsored by Gilead sorted 124 patients with biopsy-proven NASH to once-daily placebo or 1, 5, 10, or $40 \mathrm{mg}$ GS-9450 for 4 weeks [135]. The trial showed a 47\% decrease in ALT for the GS-9450 treatment group ( $p<0.001$ vs. placebo). The percentage of patients with normal ALT levels rose from $0 \%$ to $35 \%$ posttreatment. GS-9450 was well tolerated with the most frequent side effect reported to be headache. No severe adverse effects were noted.

Emricasan (IDN-6556, Conatus Pharmaceuticals Inc., San Diego, California) also acts as a caspase inhibitor. In one study, mice were fed a high-fat diet and subsequently found to have a fivefold increase in hepatocyte apoptosis, consistent with a 1.5-fold and 1.3-fold increase in caspase- 3 and caspase- 8 activity, respectively [138]. Treatment with IDN-6556 reduced cellular apoptosis and decreased serum AST and ALT levels. Hepatic steatosis measured by liver triglycerides content was unchanged. However, both a-SMA, a marker for hepatic stellate cell activation and surrogate measurement for fibrosis, and overall fibrosis score were reduced, suggesting that IDN-6556 can attenuate hepatocyte apoptosis and could potentially be used as an antifibrotic therapy for NASH. Conatus recently sponsored a phase 2, double-blinded, randomized controlled trial in which 38 patients with NASH and elevated transaminases were randomized to either IDN-6556 $25 \mathrm{mg}$ or placebo twice daily for 28 days [139]. Baseline levels of cCK18M/M30, a caspase-cleaved substrate, were found to be high in patients with NASH. Treatment with IDN-6556 was associated with a 30\% reduction compared to placebo. Although ALT was also significantly reduced in the treatment group, no changes were seen in weight, cholesterol, HDL, LDL, or triglycerides. IDN-6556 was generally well tolerated throughout the study, although one patient was reported to have cellulitis and another acute GI bleed. Neither event was deemed by the investigator to be attributed to treatment. Given these results, Conatus has proceeded with another phase 2 trial evaluating treatment with emricasan ( 5 or $50 \mathrm{mg}$, given twice daily compared to placebo) in NASH patients with liver fibrosis (but not cirrhosis). Outcome measures include fibrosis improvement by at least one stage without worsening of steatohepatitis; steatohepatitis resolution based on liver biopsy; and improvement in NAS and ALT. 


\section{Potential development issues}

It is inadequate for drugs that target NASH to be effective solely for histological improvement. They should also contribute to improvement in the metabolic profile in NAFLD/NASH patients. It will be important for the drugs to yield improved lipid panels, decreased insulin resistance, and possibly weight loss. The duration of treatments that will be required is not definitively known. However, there is convincing evidence that treatments will be used for extended periods of time in those who fail to lose weight. Therefore, drugs with the fewest and least problematic adverse effects will have a substantial advantage. One concern related to long-term treatment assessment is that the current primary outcome in NASH trials requires liver biopsy, the repetition of which is problematic in long-term studies. New noninvasive imaging techniques have been shown to be accurate for assessment of steatosis and fibrosis, including magnetic resonance imaging-estimated proton density fat fraction (MRI-PDFF) [140] and magnetic resonance elastography (MRE) [140,141]. However, the inflammation component of NASH is still lacking biomarkers, and new reliable markers are urgently needed.

\section{Conclusion}

The prevalence of NAFLD is rising rapidly and is expected to continue increasing with the growing epidemic of metabolic syndrome. There is a large unmet need for therapeutic agents to prevent and reverse NASH, as currently there are no FDA-approved medications for this condition. As the pathogenesis of NASH has been shown to be complex and multifactorial, there are a myriad of treatments in the phase $2 / 3$ clinical trial pipeline including agents directed at addressing steatosis and lipogenesis, immune modulation, oxidative stress, apoptosis, and fibrosis. Future research should be directed toward finding agents that can improve liver histology, have favorable cardiovascular and metabolic effects, and demonstrate long-term safety.

\section{Expert opinion}

The treatment of NASH has been shown to be complex and to necessitate targeting multiple pathways. The drugs investigated to date have been shown to yield far less than $50 \%$ improvement in histological outcome. In addition, noninvasive biomarkers to differentiate NAFL from NASH are not yet available, and the long-term follow-up can be challenging if repeating liver biopsy is required. New techniques such as MRI-PDFF and MR elastography have been shown to be very precise in quantifying liver fat and fibrosis, and we believe that they should be considered for long-term follow-up in both clinical practice and clinical trial $[140,141]$.

To date, although some medications have shown efficacy, the long-term effects are unknown. Indeed, treatment duration has not been defined, and no consensus has been reached for treatment end point 'stopping rules'. We believe that NASH treatment will require using multiple drugs to achieve maximum therapeutic effect. However, combination therapy will need to be tailored toward the disease stage and severity. For patients with NASH and stage I fibrosis, treatment will be different than for those with stage III/IV fibrosis. In the first 
population, a combination of drugs that target steatosis and oxidative stress and/or an immune modulator might be the best approach. In the second population, a combination of antifibrotic agents [142] and an immune modulator and/or agents that target oxidative stress might be the optimal treatment.

Furthermore, there is emerging evidence in our field that NASH patients might have different underlying pathological pathways that are unique to each group of NASH patients. This suggests that NASH patients can be classified by phenotypes, and rather than using combination therapy to achieve optimal effect, a therapy targeted to the underlying pathological process might be the treatment of choice. This approach of personalized medicine awaits more evidence. Finally, risk factors associated with NAFLD and NASH should be considered and modified. For instance, NAFLD/NASH have been associated with dyslipidemia. Given the fact that the mortality of NAFLD/NASH patients may be linked to cardiovascular disease and that statins may improve NAFLD/NASH, they might be considered as part of the treatment regimen [143-146].

Further studies and research will guide us to the best approach in patients with NAFLD/ NASH. It will be essential in the next few years to determine which agents are most effective and have the fewest adverse effects. We also believe that the concept of combination therapy to reach maximum resolution of the histological findings needs to be explored further. Meanwhile, we need to establish: (1) long-term strategies to monitor the disease (such as using MRI techniques or new accurate noninvasive biomarkers) and (2) stopping points in NASH treatment (such as resolution of steatosis on high-quality imaging such as MRIs). We expect that new medications will be approved in the next few years followed by accepted strategies to target disease cure such as combination therapy and/or personalized medicine. In summary, this is an exciting era of NAFLD/NASH treatment progress. With multiple agents currently being developed, there may soon be an ability to effectively slow or even reverse the disease process in many NAFLD/NASH patients.

\section{Acknowledgments}

The study was conducted at the Clinical and Translational Research Institute, University of California at San Diego.

Funding

R Loomba is supported in part by the American Gastroenterological Association (AGA) Foundation -Sucampo ASP Designated Research Award in Geriatric Gastroenterology and by a T. Franklin Williams Scholarship Award; Funding provided by: Atlantic Philanthropies, Inc, the John A. Hartford Foundation, the Association of Specialty Professors, and the American Gastroenterological Association and grant K23-DK090303 and R01-DK106419-01.

\section{References}

Papers of special note have been highlighted as either of interest $(\bullet)$ or of considerable interest $(\bullet \bullet)$ to readers.

1. Younossi ZM, Stepanova M, Afendy M, et al. Changes in the prevalence of the most common causes of chronic liver diseases in the United States from 1988 to 2008. Clin Gastroenterol Hepatol. 2011; 9:524-530. [PubMed: 21440669]

2••. Setiawan, VW., Stram, DO., Porcel, J., et al. Prevalence of chronic liver disease and cirrhosis by underlying cause in understudied ethnic groups: the multiethnic cohort. Hepatology. 2016 Jun 15. [Epub ahead of print]. Available from: http://www.ncbi.nlm.nih.gov/pubmed/ 
27301913Epidemiology study in a multiethnic cohort from the US showing the NAFLD is the most common cause of CLD overall and of cirrhosis in special ethnic groups

3. Charlton M. Nonalcoholic fatty liver disease: a review of current understanding and future impact. Clin Gastroenterol Hepatol. 2004; 2:1048-1058. [PubMed: 15625647]

4. Vuppalanchi R, Chalasani N. Nonalcoholic fatty liver disease and nonalcoholic steatohepatitis: selected practical issues in their evaluation and management. Hepatology. 2009; 49:306-317. [PubMed: 19065650]

5. Yilmaz Y, Younossi ZM. Obesity-associated nonalcoholic fatty liver disease. Clin Liver Dis. 2014; 18:19-31. [PubMed: 24274862]

6•. LaBrecque DR, Abbas Z, et al. Review Team. World Gastroenterology Organisation global guidelines: nonalcoholic fatty liver disease and nonalcoholic steatohepatitis. J Clin Gastroenterol. 2014; 48:467-473. The World Gastroenterology Organisation guidelines on NAFLD/NASH. [PubMed: 24921212]

7. McPherson S, Hardy T, Henderson E, et al. Evidence of NAFLD progression from steatosis to fibrosing-steatohepatitis using paired biopsies: implications for prognosis and clinical management. J Hepatol. 2015; 62:1148-1155. [PubMed: 25477264]

8. Singh S, Allen AM, Wang Z, et al. Fibrosis progression in nonalcoholic fatty liver vs nonalcoholic steatohepatitis: a systematic review and meta-analysis of paired-biopsy studies. Clin Gastroenterol Hepatol. 2015; 13:643-54. e1-9. quiz e39-40. [PubMed: 24768810]

9. Ekstedt M, Franzen LE, Mathiesen UL, et al. Long-term follow-up of patients with NAFLD and elevated liver enzymes. Hepatology. 2006; 44:865-873. [PubMed: 17006923]

10. Finelli C, Tarantino G. Is there any consensus as to what diet or lifestyle approach is the right one for NAFLD patients? J Gastrointestin Liver Dis. 2012; 21:293-302. [PubMed: 23012671]

$11 \bullet$. Chalasani N, Younossi Z, Lavine JE, et al. The diagnosis and management of non-alcoholic fatty liver disease: practice guideline by the American Association for the Study of Liver Diseases, American College of Gastroenterology, and the American Gastroenterological Association. Am J Gastroenterol. 2012; 107:811-826. The American Association for the Study of Liver Diseases guidelines on NAFLD. [PubMed: 22641309]

12. Adams LA, Lymp JF, St Sauver J, et al. The natural history of nonalcoholic fatty liver disease: a population-based cohort study. Gastroenterology. 2005; 129:113-121. [PubMed: 16012941]

13. Dam-Larsen S, Becker U, Franzmann MB, et al. Final results of a long-term, clinical follow-up in fatty liver patients. Scand J Gastroenterol. 2009; 44:1236-1243. [PubMed: 19670076]

14. Dunn W, Xu R, Wingard DL, et al. Suspected nonalcoholic fatty liver disease and mortality risk in a population-based cohort study. Am J Gastroenterol. 2008; 103:2263-2271. [PubMed: 18684196]

15. Stepanova M, Rafiq N, Younossi ZM. Components of metabolic syndrome are independent predictors of mortality in patients with chronic liver disease: a population-based study. Gut. 2010; 59:1410-1415. [PubMed: 20660697]

16. Chalasani NP, Sanyal AJ, Kowdley KV, et al. Pioglitazone versus vitamin E versus placebo for the treatment of non-diabetic patients with non-alcoholic steatohepatitis: PIVENS trial design. Contemp Clin Trials. 2009; 30:88-96. [PubMed: 18804555]

17•. Spengler EK, Loomba R. Recommendations for diagnosis, referral for liver biopsy, and treatment of nonalcoholic fatty liver disease and nonalcoholic steatohepatitis. Mayo Clin Proc. 2015; 90:1233-1246. Review paper on work up and treatment for NAFLD/NASH. [PubMed: 26219858]

18. Neuschwander-Tetri BA, Loomba R, Sanyal AJ, et al. Farnesoid X nuclear receptor ligand obeticholic acid for non-cirrhotic, nonalcoholic steatohepatitis (FLINT): a multicentre, randomised, placebo-controlled trial. Lancet. 2015; 385:956-965. [PubMed: 25468160]

19. Van Wagner LB, Koppe SW, Brunt EM, et al. Pentoxifylline for the treatment of non-alcoholic steatohepatitis: a randomized controlled trial. Ann Hepatol. 2011; 10:277-286. [PubMed: 21677329]

20. Zein CO, Lopez R, Fu X, et al. Pentoxifylline decreases oxidized lipid products in nonalcoholic steatohepatitis: new evidence on the potential therapeutic mechanism. Hepatology. 2012; 56:12911299. [PubMed: 22505276] 
21••. Kleiner DE, Brunt EM, Van Natta M, et al. Design and validation of a histological scoring system for nonalcoholic fatty liver disease. Hepatology. 2005; 41:1313-1321. Paper on the most validated histological scoring system in NASH. [PubMed: 15915461]

22. Browning JD, Horton JD. Molecular mediators of hepatic steatosis and liver injury. J Clin Invest. 2004; 114:147-152. [PubMed: 15254578]

23. Cohen JC, Horton JD, Hobbs HH. Human fatty liver disease: old questions and new insights. Science. 2011; 332:1519-1523. [PubMed: 21700865]

24. Hassan K, Bhalla V, El Regal ME, et al. Nonalcoholic fatty liver disease: a comprehensive review of a growing epidemic. World J Gastroenterol. 2014; 20:12082-12101. [PubMed: 25232245]

25. Postic C, Girard J. Contribution of de novo fatty acid synthesis to hepatic steatosis and insulin resistance: lessons from genetically engineered mice. J Clin Invest. 2008; 118:829-838. [PubMed: 18317565]

26. Fromenty B, Robin MA, Igoudjil A, et al. The ins and outs of mitochondrial dysfunction in NASH. Diabetes Metab. 2004; 30:121-138. [PubMed: 15223984]

27. Sunny NE, Parks EJ, Browning JD, et al. Excessive hepatic mitochondrial TCA cycle and gluconeogenesis in humans with nonalcoholic fatty liver disease. Cell Metab. 2011; 14:804-810. [PubMed: 22152305]

28. Sanyal AJ, Campbell-Sargent C, Mirshahi F, et al. Nonalcoholic steatohepatitis: association of insulin resistance and mitochondrial abnormalities. Gastroenterology. 2001; 120:1183-1192. [PubMed: 11266382]

29•. Noureddin M, Mato JM, Lu SC. Nonalcoholic fatty liver disease: update on pathogenesis, diagnosis, treatment and the role of S-adenosylmethionine. Exp Biol Med (Maywood). 2015; 240:809-820. Review paper on the pathogenesis of NAFLD/NASH. [PubMed: 25873078]

30. Cai D, Yuan M, Frantz DF, et al. Local and systemic insulin resistance resulting from hepatic activation of IKK-beta and NF-kappaB. Nat Med. 2005; 11:183-190. [PubMed: 15685173]

31. Haukeland JW, Damas JK, Konopski Z, et al. Systemic inflammation in nonalcoholic fatty liver disease is characterized by elevated levels of CCL2. J Hepatol. 2006; 44:1167-1174. [PubMed: 16618517]

32. Hui JM, Hodge A, Farrell GC, et al. Beyond insulin resistance in NASH: TNF-alpha or adiponectin? Hepatology. 2004; 40:46-54. [PubMed: 15239085]

33. Crespo J, Cayon A, Fernandez-Gil P, et al. Gene expression of tumor necrosis factor alpha and TNF-receptors, p55 and p75, in nonalcoholic steatohepatitis patients. Hepatology. 2001; 34:11581163. [PubMed: 11732005]

34. Yuan M, Konstantopoulos N, Lee J, et al. Reversal of obesity- and diet-induced insulin resistance with salicylates or targeted disruption of Ikkbeta. Science. 2001; 293:1673-1677. [PubMed: 11533494]

35. Lee YA, Wallace MC, Friedman SL. Pathobiology of liver fibrosis: a translational success story. Gut. 2015; 64:830-841. [PubMed: 25681399]

36. Miura K, Seki E, Ohnishi H, et al. Role of toll-like receptors and their downstream molecules in the development of nonalcoholic fatty liver disease. Gastroenterol Res Pract. 2010; 2010:362847. [PubMed: 21274430]

37. Seki E, Brenner DA. Toll-like receptors and adaptor molecules in liver disease: update. Hepatology. 2008; 48:322-335. [PubMed: 18506843]

38. Cope K, Risby T, Diehl AM. Increased gastrointestinal ethanol production in obese mice: implications for fatty liver disease pathogenesis. Gastroenterology. 2000; 119:1340-1347. [PubMed: 11054393]

39. Solga SF, Diehl AM. Nonalcoholic fatty liver disease: lumen-liver interactions and possible role for probiotics. J Hepatol. 2003; 38:681-687. [PubMed: 12713883]

40. Friedman SL. Preface. Hepatic fibrosis: pathogenesis, diagnosis, and emerging therapies. Clin Liver Dis. 2008; 12:xiii-xiv.

41. Henderson NC, Iredale JP. Liver fibrosis: cellular mechanisms of progression and resolution. Clin Sci (Lond). 2007; 112:265-280. [PubMed: 17261089] 
42. Oakley F, Teoh V, Ching ASG, et al. Angiotensin II activates I kappaB kinase phosphorylation of RelA at Ser 536 to promote myofibroblast survival and liver fibrosis. Gastroenterology. 2009; 136:2334-2344. e1. [PubMed: 19303015]

43. Albanis E, Friedman SL. Antifibrotic agents for liver disease. Am J Transplant. 2006; 6:12-19. [PubMed: 16433751]

44. Friedman SL, Rockey DC, Bissell DM. Hepatic fibrosis 2006: report of the third AASLD single topic conference. Hepatology. 2007; 45:242-249. [PubMed: 17187439]

45. Dobrzyn A, Ntambi JM. Stearoyl-CoA desaturase as a new drug target for obesity treatment. Obes Rev. 2005; 6:169-174. [PubMed: 15836467]

46. Dobrzyn P, Dobrzyn A, Miyazaki M, et al. Stearoyl-CoA desaturase 1 deficiency increases fatty acid oxidation by activating AMP-activated protein kinase in liver. Proc Natl Acad Sci USA. 2004; 101:6409-6414. [PubMed: 15096593]

47. Leikin-Frenkel A, Goldiner I, Leikin-Gobbi D, et al. Treatment of preestablished diet-induced fatty liver by oral fatty acid-bile acid conjugates in rodents. Eur J Gastroenterol Hepatol. 2008; 20:1205-1213. [PubMed: 18989145]

48. Safadi R, Konikoff FM, Mahamid M, et al. The fatty acid-bile acid conjugate aramchol reduces liver fat content in patients with non-alcoholic fatty liver disease. Clin Gastroenterol Hepatol. 2014; 12:2085-91. e1. [PubMed: 24815326]

49. Li H, Zhang J, Jia W. Fibroblast growth factor 21: a novel metabolic regulator from pharmacology to physiology. Front Med. 2013; 7:25-30. [PubMed: 23358894]

50. Chen W, Hoo RL, Konishi M, et al. Growth hormone induces hepatic production of fibroblast growth factor 21 through a mechanism dependent on lipolysis in adipocytes. J Biol Chem. 2011; 286:34559-34566. [PubMed: 21849508]

51. Li K, Li L, Yang M, et al. The effects of fibroblast growth factor-21 knockdown and overexpression on its signaling pathway and glucose-lipid metabolism in vitro. Mol Cell Endocrinol. 2012; 348:21-26. [PubMed: 21801806]

52. Zhang Y, Lei T, Huang JF, et al. The link between fibroblast growth factor 21 and sterol regulatory element binding protein 1c during lipogenesis in hepatocytes. Mol Cell Endocrinol. 2011; 342:4147. [PubMed: 21664250]

53. Liu J, Xu Y, Hu Y, et al. The role of fibroblast growth factor 21 in the pathogenesis of nonalcoholic fatty liver disease and implications for therapy. Metabolism. 2015; 64:380-390. [PubMed: 25516477]

54. Coskun T, Bina HA, Schneider MA, et al. Fibroblast growth factor 21 corrects obesity in mice. Endocrinology. 2008; 149:6018-6027. [PubMed: 18687777]

55. Li Y, Wong K, Giles A, et al. Hepatic SIRT1 attenuates hepatic steatosis and controls energy balance in mice by inducing fibroblast growth factor 21 . Gastroenterology. 2014; 146:539-49. e7. [PubMed: 24184811]

56. Xu J, Lloyd DJ, Hale C, et al. Fibroblast growth factor 21 reverses hepatic steatosis, increases energy expenditure, and improves insulin sensitivity in diet-induced obese mice. Diabetes. 2009; 58:250-259. [PubMed: 18840786]

57. Staels B, Rubenstrunk A, Noel B, et al. Hepatoprotective effects of the dual peroxisome proliferator-activated receptor alpha/delta agonist, GFT505, in rodent models of nonalcoholic fatty liver disease/nonalcoholic steatohepatitis. Hepatology. 2013; 58:1941-1952. [PubMed: 23703580]

58. Ratziu V, Harrison SA, Francque S, et al. Elafibranor, an agonist of the peroxisome proliferatoractivated receptor-alpha and -delta, induces resolution of nonalcoholic steatohepatitis without fibrosis worsening. Gastroenterology. 2016; 150:1147-1159. e5. [PubMed: 26874076]

59. Chia CW, Egan JM. Incretin-based therapies in type 2 diabetes mellitus. J Clin Endocrinol Metab. 2008; 93:3703-3716. [PubMed: 18628530]

60. Nauck MA, Kleine N, Orskov C, et al. Normalization of fasting hyperglycaemia by exogenous glucagon-like peptide 1 (7-36 amide) in type 2 (non-insulin-dependent) diabetic patients. Diabetologia. 1993; 36:741-744. [PubMed: 8405741]

61. Barry-Hamilton V, Spangler R, Marshall D, et al. Allosteric inhibition of lysyl oxidase-like-2 impedes the development of a pathologic microenvironment. Nat Med. 2010; 16:1009-1017. [PubMed: 20818376] 
62. Cuthbertson DJ, Irwin A, Gardner CJ, et al. Improved glycaemia correlates with liver fat reduction in obese, type 2 diabetes, patients given glucagon-like peptide-1 (GLP-1) receptor agonists. PLoS One. 2012; 7:e50117. [PubMed: 23236362]

63. Shirakawa J, Fujii H, Ohnuma K, et al. Diet-induced adipose tissue inflammation and liver steatosis are prevented by DPP-4 inhibition in diabetic mice. Diabetes. 2011; 60:1246-1257. [PubMed: 21330637]

64. Svegliati-Baroni G, Saccomanno S, Rychlicki C, et al. Glucagon-like peptide-1 receptor activation stimulates hepatic lipid oxidation and restores hepatic signalling alteration induced by a high-fat diet in nonalcoholic steatohepatitis. Liver Int. 2011; 31:1285-1297. [PubMed: 21745271]

65. Trevaskis JL, Griffin PS, Wittmer C, et al. Glucagon-like peptide-1 receptor agonism improves metabolic, biochemical, and histopathological indices of nonalcoholic steatohepatitis in mice. Am J Physiol Gastrointest Liver Physiol. 2012; 302:G762-72. [PubMed: 22268099]

66. Armstrong MJ, Gaunt P, Aithal GP, et al. Liraglutide safety and efficacy in patients with nonalcoholic steatohepatitis (LEAN): a multicentre, double-blind, randomised, placebo-controlled phase 2 study. Lancet. 2016; 387(10019):679-690. [PubMed: 26608256]

67. Shimozono R, Asaoka Y, Yoshizawa Y, et al. Nrf2 activators attenuate the progression of nonalcoholic steatohepatitis-related fibrosis in a dietary rat model. Mol Pharmacol. 2013; 84:6270. [PubMed: 23592516]

68. Kim, W., Sung Lee, J., Kyon Lee, C., et al. Antisteatotic efficacy and safety of the liver X receptor alpha inhibitor, dithiolethione in patients with nonalcoholic fatty liver disease. 65th Annual Meeting of the American Association for the Study of Liver Diseases (AASLD); 2014 Nov 7-11; Boston, MA.

69. Yilmaz Y, Yonal O, Deyneli O, et al. Effects of sitagliptin in diabetic patients with nonalcoholic steatohepatitis. Acta Gastroenterol Belg. 2012; 75:240-244. [PubMed: 22870790]

70. Cui J, Philo L, Nguyen P, et al. Sitagliptin vs. placebo for nonalcoholic fatty liver disease: a randomized controlled trial. J Hepatol. 2016; 65(2):369-376. [PubMed: 27151177]

71. Takeuchi O, Akira S. Pattern recognition receptors and inflammation. Cell. 2010; 140:805-820. [PubMed: 20303872]

72. Yamamoto M, Takeda K. Current views of toll-like receptor signaling pathways. Gastroenterol Res Pract. 2010; 2010:240365. [PubMed: 21197425]

73. Chen CJ, Kono H, Golenbock D, et al. Identification of a key pathway required for the sterile inflammatory response triggered by dying cells. Nat Med. 2007; 13:851-856. [PubMed: 17572686]

74. Zhang Q, Raoof M, Chen Y, et al. Circulating mitochondrial DAMPs cause inflammatory responses to injury. Nature. 2010; 464:104-107. [PubMed: 20203610]

75. Isogawa M, Robek MD, Furuichi Y, et al. Toll-like receptor signaling inhibits hepatitis B virus replication in vivo. J Virol. 2005; 79:7269-7272. [PubMed: 15890966]

76. Seki E, Tsutsui H, Nakano H, et al. Lipopolysaccharide-induced IL-18 secretion from murine Kupffer cells independently of myeloid differentiation factor 88 that is critically involved in induction of production of IL-12 and IL-1beta. J Immunol. 2001; 166:2651-2657. [PubMed: 11160328]

77. Wu J, Meng Z, Jiang M, et al. Toll-like receptor-induced innate immune responses in nonparenchymal liver cells are cell type-specific. Immunology. 2010; 129:363-374. [PubMed: 19922426]

78. Paik YH, Schwabe RF, Bataller R, et al. Toll-like receptor 4 mediates inflammatory signaling by bacterial lipopolysaccharide in human hepatic stellate cells. Hepatology. 2003; 37:1043-1055. [PubMed: 12717385]

79. Seki E, De Minicis S, Osterreicher CH, et al. TLR4 enhances TGF-beta signaling and hepatic fibrosis. Nat Med. 2007; 13:1324-1332. [PubMed: 17952090]

80. Watanabe A, Hashmi A, Gomes DA, et al. Apoptotic hepatocyte DNA inhibits hepatic stellate cell chemotaxis via toll-like receptor 9. Hepatology. 2007; 46:1509-1518. [PubMed: 17705260]

81. Cengiz M, Ozenirler S, Elbeg S. Role of serum toll-like receptors 2 and 4 in non-alcoholic steatohepatitis and liver fibrosis. J Gastroenterol Hepatol. 2015; 30:1190-1196. [PubMed: 25684563] 
82. Csak T, Velayudham A, Hritz I, et al. Deficiency in myeloid differentiation factor-2 and toll-like receptor 4 expression attenuates nonalcoholic steatohepatitis and fibrosis in mice. Am J Physiol Gastrointest Liver Physiol. 2011; 300:G433-41. [PubMed: 21233280]

83. Ley RE, Turnbaugh PJ, Klein S, et al. Microbial ecology: human gut microbes associated with obesity. Nature. 2006; 444:1022-1023. [PubMed: 17183309]

84. Turnbaugh PJ, Gordon JI. The core gut microbiome, energy balance and obesity. J Physiol. 2009; 587:4153-4158. [PubMed: 19491241]

85. Miele L, Valenza V, La Torre G, et al. Increased intestinal permeability and tight junction alterations in nonalcoholic fatty liver disease. Hepatology. 2009; 49:1877-1887. [PubMed: 19291785]

86. Iacono A, Raso GM, Canani RB, et al. Probiotics as an emerging therapeutic strategy to treat NAFLD: focus on molecular and biochemical mechanisms. J Nutr Biochem. 2011; 22:699-711. [PubMed: 21292470]

87. Aller R, De Luis DA, Izaola O, et al. Effect of a probiotic on liver aminotransferases in nonalcoholic fatty liver disease patients: a double blind randomized clinical trial. Eur Rev Med Pharmacol Sci. 2011; 15:1090-1095. [PubMed: 22013734]

88. Malaguarnera M, Vacante M, Antic T, et al. Bifidobacterium longum with fructooligosaccharides in patients with non alcoholic steatohepatitis. Dig Dis Sci. 2012; 57:545-553. [PubMed: 21901256]

89. Eslamparast T, Poustchi H, Zamani F, et al. Synbiotic supplementation in nonalcoholic fatty liver disease: a randomized, double-blind, placebo-controlled pilot study. Am J Clin Nutr. 2014; 99:535-542. [PubMed: 24401715]

90. Kanoh S, Rubin BK. Mechanisms of action and clinical application of macrolides as immunomodulatory medications. Clin Microbiol Rev. 2010; 23:590-615. [PubMed: 20610825]

91. Kobayashi Y, Wada H, Rossios C, et al. A novel macrolide solithromycin exerts superior antiinflammatory effect via NF-kappaB inhibition. J Pharmacol Exp Ther. 2013; 345:76-84. [PubMed: 23359665]

92. Fernandes P, Hashiguchi T, Fujii M, et al. Anti-NASH effects of solithromycin in NASH-HCC mouse model. Gastroenterology. 2014; 146:S-145.

93. Jiang YJ, Teichert AE, Fong F, et al. 1alpha,25(OH)2-dihydroxyvita-min D3/VDR protects the skin from UVB-induced tumor formation by interacting with the beta-catenin pathway. J Steroid Biochem Mol Biol. 2013; 136:229-232. [PubMed: 23026511]

94. Chun RF, Liu PT, Modlin RL, et al. Impact of vitamin D on immune function: lessons learned from genome-wide analysis. Front Physiol. 2014; 5:151. [PubMed: 24795646]

95. Maestro B, Davila N, Carranza MC, et al. Identification of a vitamin D response element in the human insulin receptor gene promoter. J Steroid Biochem Mol Biol. 2003; 84:223-230. [PubMed: 12711007]

96. Zeitz U, Weber K, Soegiarto DW, et al. Impaired insulin secretory capacity in mice lacking a functional vitamin D receptor. FASEB J. 2003; 17:509-511. [PubMed: 12551842]

97. Holick MF. Vitamin D deficiency. N Engl J Med. 2007; 357:266-281. [PubMed: 17634462]

98. Verstuyf A, Carmeliet G, Bouillon R, et al. Vitamin D: a pleiotropic hormone. Kidney Int. 2010; 78:140-145. [PubMed: 20182414]

99. Ding N, Yu RT, Subramaniam N, et al. A vitamin D receptor/SMAD genomic circuit gates hepatic fibrotic response. Cell. 2013; 153:601-613. [PubMed: 23622244]

100. Nakano T, Cheng YF, Lai CY, et al. Impact of artificial sunlight therapy on the progress of nonalcoholic fatty liver disease in rats. J Hepatol. 2011; 55:415-425. [PubMed: 21184788]

101. Eliades M, Spyrou E, Agrawal N, et al. Meta-analysis: vitamin D and non-alcoholic fatty liver disease. Aliment Pharmacol Ther. 2013; 38:246-254. [PubMed: 23786213]

102. Sharifi N, Amani R, Hajiani E, et al. Does vitamin D improve liver enzymes, oxidative stress, and inflammatory biomarkers in adults with nonalcoholic fatty liver disease? A randomized clinical trial. Endocrine. 2014; 47:70-80. [PubMed: 24968737]

103. Karnik, S. Pharmacological inhibition of apoptosis signal-regulating kinase 1 (ASK1) in a murine model of NASH with pre-existing disease blocks fibrosis, steatosis, and insulin resistance. The

Expert Opin Emerg Drugs. Author manuscript; available in PMC 2018 April 18. 
Liver Meeting 2014; 2014 Nov 7-11; Boston, MA. American Association for the Study of Liver Diseases (AASLD);

104. Stulnig TM. Immunomodulation by polyunsaturated fatty acids: mechanisms and effects. Int Arch Allergy Immunol. 2003; 132:310-321. [PubMed: 14707462]

105. Bezard J, Blond JP, Bernard A, et al. The metabolism and availability of essential fatty acids in animal and human tissues. Reprod Nutr Dev. 1994; 34:539-568. [PubMed: 7840871]

106. Das UN. Biological significance of essential fatty acids. J Assoc Physicians India. 2006; 54:309319. [PubMed: 16944615]

107. Levy JR, Clore JN, Stevens W. Dietary n-3 polyunsaturated fatty acids decrease hepatic triglycerides in Fischer 344 rats. Hepatology. 2004; 39:608-616. [PubMed: 14999679]

108. Sekiya M, Yahagi N, Matsuzaka T, et al. Polyunsaturated fatty acids ameliorate hepatic steatosis in obese mice by SREBP-1 suppression. Hepatology. 2003; 38:1529-1539. [PubMed: 14647064]

109. Teran-Garcia M, Adamson AW, Yu G, et al. Polyunsaturated fatty acid suppression of fatty acid synthase (FASN): evidence for dietary modulation of NF-Y binding to the Fasn promoter by SREBP-1c. Biochem J. 2007; 402:591-600. [PubMed: 17313375]

110. Kersten S, Seydoux J, Peters JM, et al. Peroxisome proliferator-activated receptor alpha mediates the adaptive response to fasting. J Clin Invest. 1999; 103:1489-1498. [PubMed: 10359558]

111. Huang T, Bhulaidok S, Cai Z, et al. Plasma phospholipids n-3 poly-unsaturated fatty acid is associated with metabolic syndrome. Mol Nutr Food Res. 2010; 54:1628-1635. [PubMed: 20540149]

112. Alfin-Slater RB, Bernick S. Changes in tissue lipids and tissue histology resulting from essential fatty acid deficiency in rats. Am J Clin Nutr. 1958; 6:613-624. [PubMed: 13594892]

113. Werner A, Havinga R, Kuipers F, et al. Treatment of EFA deficiency with dietary triglycerides or phospholipids in a murine model of extrahepatic cholestasis. Am J Physiol Gastrointest Liver Physiol. 2004; 286:G822-G832. [PubMed: 14670824]

114. Alwayn IP, Andersson C, Zauscher B, et al. Omega-3 fatty acids improve hepatic steatosis in a murine model: potential implications for the marginal steatotic liver donor. Transplantation. 2005; 79:606-608. [PubMed: 15753852]

115. Lu SC, Mato JM. S-adenosylmethionine in liver health, injury, and cancer. Physiol Rev. 2012; 92:1515-1542. [PubMed: 23073625]

116. Mato JM, Martinez-Chantar ML, Lu SC. S-adenosylmethionine metabolism and liver disease. Ann Hepatol. 2013; 12:183-189. [PubMed: 23396728]

117. Mato JM, Lu SC. Role of S-adenosyl-L-methionine in liver health and injury. Hepatology. 2007; 45:1306-1312. [PubMed: 17464973]

118. Bottiglieri T. S-Adenosyl-L-methionine (SAMe): from the bench to the bedside-molecular basis of a pleiotrophic molecule. Am J Clin Nutr. 2002; 76:1151S-7S. [PubMed: 12418493]

119. Li Z, Agellon LB, Allen TM, et al. The ratio of phosphatidylcholine to phosphatidylethanolamine influences membrane integrity and steatohepatitis. Cell Metab. 2006; 3:321-331. [PubMed: 16679290]

120. Mato JM, Camara J, Fernandez de Paz J, et al. S-adenosylmethionine in alcoholic liver cirrhosis: a randomized, placebo-controlled, double-blind, multicenter clinical trial. J Hepatol. 1999; 30:1081-1089. [PubMed: 10406187]

121. Hong F, Chou H, Friedman SL. Significant anti-fibrotic activity of cenicriviroc, a dual CCR2/ CCR5 antagonist, in a rat model of thioacetamide-induced liver fibrosis and cirrhosis. Hepatology. 2013; 58:1381A-1382A.

122. Lefebvre E, Hashiguchi T, Jenkins H, et al. Antifibrotic and anti-inflammatory activity of the dual CCR2 and CCR5 antagonist cenicriviroc in a mouse model of NASH. Hepatology. 2013; 58:221A-222A.

123. Di Lella S, Sundblad V, Cerliani JP, et al. When galectins recognize glycans: from biochemistry to physiology and back again. Biochemistry. 2011; 50:7842-7857. [PubMed: 21848324]

124. Yang RY, Rabinovich GA, Liu FT. Galectins: structure, function and therapeutic potential. Expert Rev Mol Med. 2008; 10:e17. [PubMed: 18549522] 
125. Henderson NC, Sethi T. The regulation of inflammation by galectin-3. Immunol Rev. 2009; 230:160-171. [PubMed: 19594635]

126. Henderson NC, Mackinnon AC, Farnworth SL, et al. Galectin-3 regulates myofibroblast activation and hepatic fibrosis. Proc Natl Acad Sci USA. 2006; 103:5060-5065. [PubMed: 16549783]

127. Mackinnon AC, Gibbons MA, Farnworth SL, et al. Regulation of transforming growth factorbeta1-driven lung fibrosis by galectin-3. Am J Respir Crit Care Med. 2012; 185:537-546. [PubMed: 22095546]

128. Harrison SA, Chalasani NP, Lawitz E, et al. Early phase 1 clinical trial results of GR-MD-02, a galectin-3 inhibitor, in patients having non-alcoholic steatohepatitis (NASH) with advanced fibrosis. Hepatology. 2014; 60:224A-227A. [PubMed: 24700550]

129. Atanasova E, Martinova F, Jelev D, et al. Alpha-2 macroglobulin is the simplest serum biomarker for liver fibrosis and fibrogenesis in chronic hepatitis C. Medinform. 2015; 2:153-164.

130. Yoshiji H, Kuriyama S, Yoshii J, et al. Angiotensin-II induces the tissue inhibitor of metalloproteinases-1 through the protein kinase-C signaling pathway in rat liver fibrosis development. Hepatol Res. 2003; 27:51-56. [PubMed: 12957207]

131. Gaedeke J, Peters H, Noble NA, et al. Angiotensin II, TGF-beta and renal fibrosis. Contrib Nephrol. 2001; 135:153-160.

132. Hirose A, Ono M, Saibara T, et al. Angiotensin II type 1 receptor blocker inhibits fibrosis in rat nonalcoholic steatohepatitis. Hepatology. 2007; 45:1375-1381. [PubMed: 17518368]

133. Yokohama S, Yoneda M, Haneda M, et al. Therapeutic efficacy of an angiotensin II receptor antagonist in patients with nonalcoholic steatohepatitis. Hepatology. 2004; 40:1222-1225. [PubMed: 15382153]

134. Moon HJ, Finney J, Ronnebaum T, et al. Human lysyl oxidase-like 2. Bioorg Chem. 2014; 57:231-241. [PubMed: 25146937]

135. Talal AH, Feron-Rigodon M, Madere J, et al. Simtuzumab, an antifibrotic monoclonal antibody against lysyl oxidase-like 2 (LOXL2) enzyme, appears safe and well tolerated in patients with liver disease of diverse etiology. J Hepatol. 2013; 58:S532.

136. Ratziu V, Sheikh MY, Sanyal AJ, et al. A phase 2, randomized, double-blind, placebo-controlled study of GS-9450 in subjects with nonalcoholic steatohepatitis. Hepatology. 2012; 55:419-428. [PubMed: 22006541]

137. Anstee QM, Concas D, Kudo H, et al. Impact of pan-caspase inhibition in animal models of established steatosis and nonalcoholic steatohepatitis. J Hepatol. 2010; 53:542-550. [PubMed: 20557969]

138. Barreyro FJ, Holod S, Finocchietto PV, et al. The pancaspase inhibitor Emricasan (IDN-6556) decreases liver injury and fibrosis in a murine model of nonalcoholic steatohepatitis. Liver Int. 2015; 35:953-966. [PubMed: 24750664]

139. Shiffman, M., Freilich, B., Vuppalanchi, R., et al. A placebo-controlled, multicenter, doubleblind, randomised trial of emricasan (IDN-6556) in subjects with nonalcoholic fatty liver disease (NAFLD) and raised transaminases. International Liver Congress 2015, the 50th Annual Meeting of the European Association for the Study of the Liver (EASL); 2015 Apr 22-26; Vienna, Austria.

140• Noureddin M, Lam J, Peterson MR, et al. Utility of magnetic resonance imaging versus histology for quantifying changes in liver fat in nonalcoholic fatty liver disease trials. Hepatology. 2013; 58:1930-1940. Study on noninvasive methods to quantify liver fat through MRI. [PubMed: 23696515]

141 . Loomba R, Wolfson T, Ang B, et al. Magnetic resonance elastography predicts advanced fibrosis in patients with nonalcoholic fatty liver disease: a prospective study. Hepatology. 2014; 60:1920 1928. Study on noninvasive methods to quantify liver fibrosis through MRI. [PubMed: 25103310]

142. Noureddin M, Anstee QM, Loomba R. Review article: emerging antifibrotic therapies in the treatment of nonalcoholic steatohepatitis. Aliment Pharmacol Ther. 2016; 43:1109-1123. [PubMed: 27061197] 
143. Dongiovanni P, Petta S, Mannisto V, et al. Statin use and nonalcoholic steatohepatitis in at risk individuals. J Hepatol. 2015; 63:705-712. [PubMed: 25980762]

144. Kargiotis K, Athyros VG, Giouleme O, et al. Resolution of nonalcoholic steatohepatitis by rosuvastatin monotherapy in patients with metabolic syndrome. World J Gastroenterol. 2015; 21:7860-7868. [PubMed: 26167086]

145. Tikkanen MJ, Fayyad R, Faergeman O, et al. Effect of intensive lipid lowering with atorvastatin on cardiovascular outcomes in coronary heart disease patients with mild-to-moderate baseline elevations in alanine aminotransferase levels. Int J Cardiol. 2013; 168:3846-3852. [PubMed: 24001698]

146. Athyros VG, Tziomalos K, Gossios TD, et al. Safety and efficacy of long-term statin treatment for cardiovascular events in patients with coronary heart disease and abnormal liver tests in the Greek Atorvastatin and Coronary Heart Disease Evaluation (GREACE) Study: a post-hoc analysis. Lancet. 2010; 376:1916-1922. [PubMed: 21109302] 

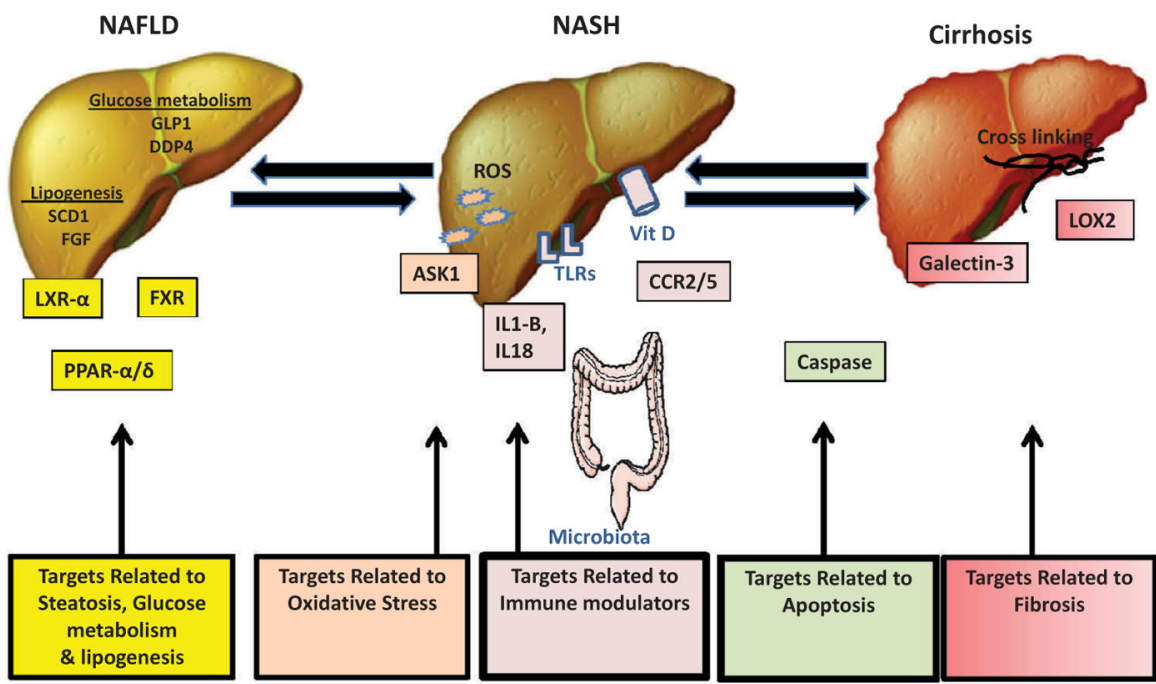

Figure 1. Promising target strategies in NASH treatment

Treatment strategies in NASH can be divided based on their targets within the pathophysiology of NASH. These include: (1) systemic targets related to steatosis, glucose metabolism and lipogenesis; (2) targets related to immune modulators; (3) targets related to oxidative stress; (4) targets related to apoptosis; and (5) targets related to fibrosis

Abbreviations: NASH: non-alcoholic steatohepatitis, GLP1: glucagon-like peptide-1, DDP4: dipeptidyl peptidase-4, SCD1: stearoyl-coenzyme A desaturase 1 enzyme, FGF: fibroblast growth factor, LXR- $a$ : liver-X-receptor- $a$, FXR: farnesoid-X receptor, PPAR- a/ $\delta$ : peroxisome proliferator-activated $a / \delta$, ROS: reactive oxidative species, ASK1: signalregulating kinase-1, IL1-B: interleukin-1B, IL18: interlukin-18, TLRs: Toll-like receptors, Vit D: Vitamin D, CCR2/5: C-C chemokine receptor type 2 AND 5, LOX2: lysyl oxidaselike 2. 


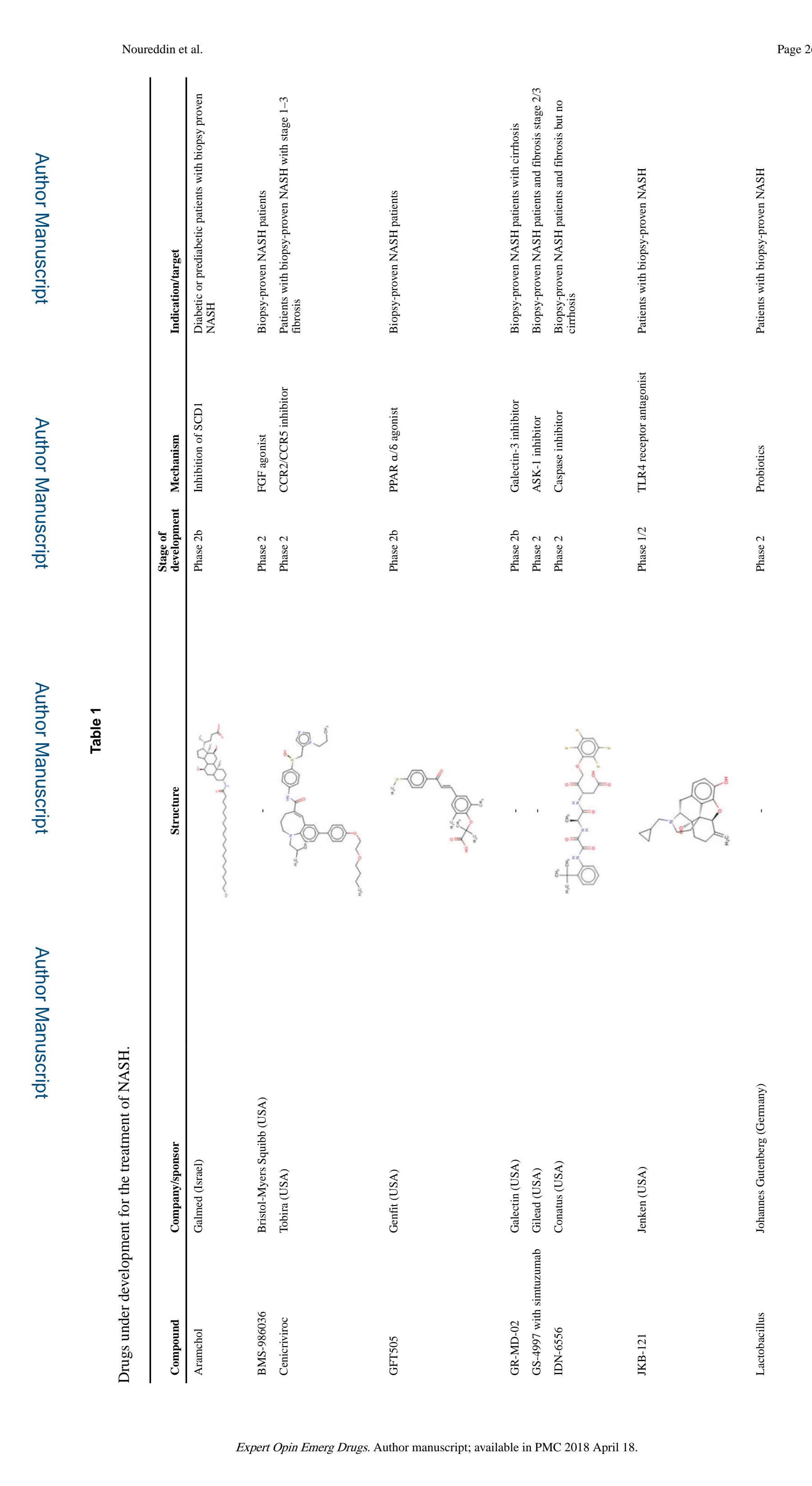




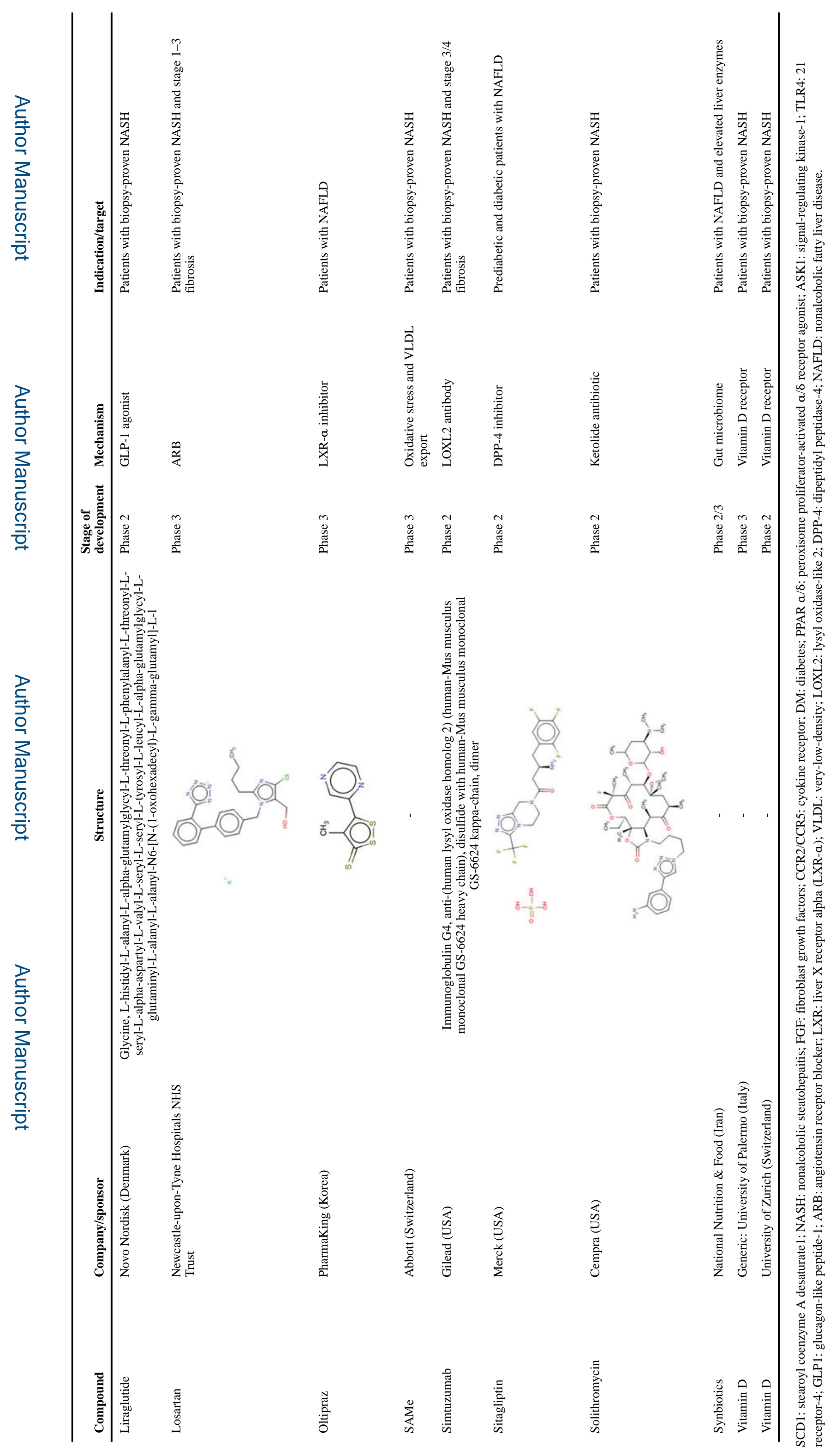

